OPEN ACCESS

Edited by:

Ljubomir Jankovic,

University of Hertfordshire,

United Kingdom

Reviewed by:

Silvio Carta,

University of Hertfordshire,

United Kingdom

Timothy O. Adekunle,

University of Hartford, United States

*Correspondence:

Robert J. Rogerson

r.j.rogerson@strath.ac.uk

Specialty section:

This article was submitted to

Urban Science,

a section of the journal

Frontiers in Built Environment

Received: 15 September 2021

Accepted: 16 November 2021

Published: 09 December 2021

Citation:

Rogerson RJ, Horgan D and Roberts JJ (2021) Integrating Artificial Urban Wetlands Into Communities: A

Pathway to Carbon Zero?

Front. Built Environ. 7:777383.

doi: 10.3389/fbuil.2021.777383

\section{Integrating Artificial Urban Wetlands Into Communities: A Pathway to Carbon Zero?}

\author{
Robert J. Rogerson ${ }^{1 *}$, Donagh Horgan ${ }^{1}$ and Jennifer J. Roberts ${ }^{2}$ \\ ${ }^{1} /$ nstitute for Future Cities, University of Strathclyde, Glasgow, United Kingdom, ${ }^{2}$ Department of Civil and Environmental \\ Engineering, University of Strathclyde, Glasgow, United Kingdom
}

In their natural state, wetland ecosystems provide an optimum natural environment for the sequestration and long-term storage of carbon dioxide $\left(\mathrm{CO}_{2}\right)$ from the atmosphere. The loss of wetlands under advancing urbanization not only diminishes this capacity for storage, but increases methane and greenhouse gases as the land is disturbed. Nevertheless, there is growing scientific interest in using artificial or constructed wetlands as a way to mitigate the impact of global climate change, with most attention on their use for water management. Using a potential integrated urban wetland site in Glasgow as a case study, this paper critically examines how artificial urban wetlands can contribute to urban net zero targets in terms of their ability for carbon sequestration, and as part of sustainability initiatives more broadly. We find there are several barriers to implementing artificial urban wetlands for carbon drawdown alone, in particular regarding land ownership constraints, uncertainties in capture efficacy and capture quantitation, and eligibility for market-based crediting schemes. These issues make it currently challenging for the carbon reduction contribution of urban wetlands to be quantified and, say, certified to generate revenue to communities through marketbased carbon crediting. However, if integrated within wider community-based sustainability initiatives, artificial urban wetlands can support multiple dimensions of sustainability, creating or supporting value far beyond water management and carbon sequestration objectives. Potential co-benefits range from areas such as health and wellbeing, biodiversity, education, food security, behavioural changes, and social care. Our findings show that for these co-benefits to be identified, maximised and realised, a place-based approach to urban wetland development must be adopted, engaging stakeholders from the project outset to define and facilitate collaboration towards shared outcomes for society, community, and environment. These findings will be relevant to any urban infrastructure development seeking to meet sustainability goals beyond carbon capture.

Keywords: net zero, urban wetlands, place-making, community participation, sustainability 


\section{INTRODUCTION}

The rapid expansion of the world's urban population has put pressure on natural landscapes at an unprecedented rate and has led to the significant loss of natural wetlands, a resource which plays a critical role in climate change, biodiversity, hydrology, and human health. Despite planning initiatives to reduce urban sprawl and promote more compact cities, wetland loss has continued with urbanisation, to the point where it is claimed between one third and one half of all wetlands have been lost over the last past two centuries (Davidson, 2014; Hu et al., 2017).

In response to such loss, constructed or artificial urban wetlands (i.e., areas of high water saturation such as fresh or saltwater marshes and lakes) have been viewed as an effective type of nature-based solution for water management and are being increasingly adopted internationally, centred on "living with and making space for water" (O’Donnell et al., 2017). Such infrastructure often aims to couple storm-water management functions and water pollution treatment within landscape-scale ecosystem conservation and/or restoration (Ahn \& Schmidt, 2019). For example, the East Kolkata Wetland complex-on the edge of the Indian city and covering some 3,000 ha-has been maintained and managed primarily to provide natural sewage treatment to remove phosphorus, to provide stormwater management, and a resource for fish (Gupta et al., 2016). In contrast, in Melbourne, Australia, more than 600 smallscale wetland areas form part of an integrated urban water management scheme, providing rich environments for wildlife alongside storm water management (Furlong et al., 2016; Oral et al., 2020).

Although constructed wetlands are one of the most common infrastructure types for urban water management schemes, there are few examples integrated into the urban environment rather than on the periphery of settlements (Ahn and Schmidt, 2019). And whilst there is an awareness that blue-green infrastructure provides health benefits such as improved air and water quality, reduced urban noise, access to greenspace, enabling urban farming, reducing energy consumption, as well as water management, research into achieving such potential benefits is in the very early stage of development (Oral et al., 2020). In part such absences reflect challenges faced by natural resource professionals in cultivating community-based support for wetland ecosystem restoration, most acutely in the setting of urban projects where alternative uses for land and especially public spaces are often prioritized by communities and urban managers. Here, often the natural dimensions of wetlands have disappeared, and communities thus struggle to envisage the character and nature of the artificial or restored wetland, and its position within their communities. Further, there is little guidance on how to integrate community stakeholders into restoration planning (Davenport et al., 2010), and few empirical studies to show how multiple benefits can be identified and fostered alongside models to promote community governance, ownership, and participation.

This paper explores how integrated constructed urban wetlands could offer more than a civil engineering solution for water management. In particular, we consider how such infrastructure could (i) contribute to carbon net zero targets for cities (ii) contribute to public health targets for cities and regions, such as air quality and access to greenspace (iii) meet local community needs and (iv) offer a viable proposition with a manageable legacy. The research draws on a proposed urban wetland site in Glasgow (Scotland) as a case study. The research critically assesses the viability and sustainability of adopting an integrated approach for urban wetland planning. Further, the case study presents a model for growing community resilience through a bottom-up process for carbon net zero aligned placemaking, where an iterative methodology for asset-based development is developed through engagement with local stakeholders as a pathway to net zero futures.

\section{A PLACE-BASED APPROACH PATHWAY TO ACHIEVING NET ZERO}

The United Nations 2030 Agenda for Sustainable Development provides a shared blueprint for peace and prosperity for people and the planet, now and into the future, as envisaged through the Sustainable Development Goals (SDGs). Scotland signed up to the SDGs in 2015, and the SDGs are reflected as vision statements in Scotland's National Outcomes (Scottish Council for Voluntary Organisations, 2018) and Scotland's 4th National Planning Framework (Scottish Government, 2020). Scotland has shown consistent international leadership on climate action (SDG13). It's world leading carbon emissions reduction targets enshrined in law commit Scotland to net zero by 2045 with the interim target to reduce emissions by $75 \%$ by 2030 compared with 1990 [Climate Change (Scotland) Act 2009 as amended by the Climate Change (Emissions Reduction Targets) (Scotland) Act 2019]. Regional climate action is even more ambitious. For example, in 2014, Glasgow City Council set targets to reduce $\mathrm{CO}_{2}$ emissions by $30 \%$ by 2020 (Glasgow City Council, 2014), achieving this goal 5 years ahead of target. In May 2019 the city council declared a climate and ecological emergency, subsequently setting a target to become carbon neutral by 2030, with a vision to become one of the most sustainable cities in Europe (Glasgow City Council, 2020).

Approaches to implement these sustainability and climate ambitions range from national to local. Scotland's Climate Change Plan 2018-2032, updated in December 2020, increases policy ambitions to cut greenhouse gas emissions across all sectors. The Plan outlines investment commitments specific to blue-green infrastructure, including the transformation of vacant and derelict land to enable maximum environmental and community benefit, nature-based solutions, and flood risk management. Importantly, the Plan also emphasizes an iterative approach to delivering the transition, and place-based approach, with ongoing planning system reforms to enable planning to focus more on places and people-in particular to support sustainable cities and communities. Indeed, SDG11 (Sustainable Cities and Communities) calls for the development of capacities to support integrated and sustainable human settlement planning and management in all countries. This is in recognition that to tackle the range of 
interconnected environmental, social and economic challenges facing cities and communities worldwide, a more holistic, collaborative, "systems thinking" approach is required (Childers et al., 2015; Maes et al., 2019).

Since the late 19th century, planners have looked to large-scale infrastructure and renewal projects as solutions to society's ills-poverty and ill-health-placing trust in engineering to build community through development processes (Jacobs, 1961). These projects often ignore the root causes of social deprivation, and are articulated in response to popular shorttermist public policy context at the time of planning (Greenfield, 2017; Finger, 2018). Bottom-up pathways towards social innovation on the other hand, that take more place-based approaches to development, face political challenges in their attempt to scale and become sustainable (Horgan and Dimitrijević, 2021). Open and agile approaches to development necessitate strong governance, ownership, and participation-qualities that can be acquired by the community through the process of social innovation itself. As a process towards sustainability, social innovation is an inherently collaborative practice in which communities participate in decision-making, design and delivery of local development (Horgan and Dimitrijević, 2021). Such participation is critical; in the same way that sustainability refers to a process in which an ecosystem develops capacities for resilience, social innovation denotes a similar process in which sustainable outcomes are identified and worked towards. Iterative participation among local or user communities in this process is therefore imperative to its success (Childers et al., 2014).

Place-based approaches to sustainable development aim to integrate wider social, economic, and environmental goals through collaboration towards shared outcomes and socially innovative propositions for the joint management of physical assets (Horgan, 2019). The approach links to Ostrom, (2007) concepts of the "urban commons" and the concept of human ecosystem transitions that recognises the "interconnectivity of organisms, including people as individuals and the members of institutions ... and their physical environments" (Ostrom, 2007; Pickett et al., 2014). As such, a place-based approach seeks to build community resilience, restore the connection between people and place, and provide tools and capabilities to support local governance (Horgan and Dimitrijević, 2018; 2019). Policy objectives such as net zero can be delivered through the adoption of place-based approaches that recognise the value of shared, coproduced social infrastructure.

In Scotland, the value of a place-based approach to development is translated into national policy, with place providing a spatial lens for developing community resilience. Responding to the need to facilitate better dialogue between agencies, the Scottish Government made a commitment to the "Place principle," a shared context for place-based work (Scottish Government, 2018): "a more joined-up, collaborative, and participative approach to services, land and buildings, across all sectors within a place, enables better outcomes for everyone and increased opportunities for people and communities to shape their own lives," with the principle request that "all those responsible for providing services and looking after assets in a place need to work and plan together, and with local communities." Specifically, social innovation in the built environment is enabled by the Scottish Government through commitments to the place-based approach in overarching national policy tools used by local agencies to develop specific targeted and contextual local development strategies (OzawaMeida and Alajmi, 2021). The Place Standard, for example, was developed with planners and architects in Scotland for communities, public agencies, voluntary groups and others, and provides a simple framework to structure conversations about place within a community ecosystem (Horgan and Dimitrijević, 2019) enabling multiple actors to collaborate, plan for and measure social impact (Mitchell et al., 2014). The Place Standard tool is used across the public service in Scotland, having been used by the National Health Service (NHS) in Scotland as a way to scope, measure, and evaluate policy interventions in health (Mitchell et al., 2014). This is supported by guidance for community engagement in Scotland's National Planning Framework, and the Community Empowerment (Scotland) Act 2015, which mandates that communities are included in decision-making on the development of community assets. Methods for placemaking and bottom-up approaches to community and urban development-such as design thinking and participatory exercises-open up decision-making to local stakeholders, and are expected to impact governance (Horgan, 2019).

\section{METHOD: A GLASGOW CASE STUDY}

We adopt a case study approach to explore how constructed urban wetlands could contribute to sustainability targets for cities and regions, including net zero ambitions, and place-based social innovation. The chosen site in the North East of Glasgow is an underdeveloped parkland adjacent to an old railway line and lying between three neighbourhoods, including some of the most deprived wards in Scotland. Using the Scottish Government's Scottish Index of Multiple Deprivation (SIMD) more than $80 \%$ of the pupils in the communities surrounding the park live in the lowest quintile (most deprived), reflected in the relatively high proportion of pupils eligible for free school meals. To the east of the park, for example, the community has a high proportion of older residents, while the number of benefit claimants is over $44 \%$ (higher than the city average) and child poverty levels are $17 \%$ higher than the city average.

Areas of the park are subjected to medium and high risks of surface water flooding (SEPA, 2021; Figure 1) which has diminished the value and use of the land. In its currently degraded state, the park is nevertheless designated for use as recreation space, with football pitches, a children's play area and pathways used for dog walking and leisure. The parkland is managed by the city council, and forms part of a "green corridor" being developed in the area connecting a number of parks and open spaces.

The park has the potential to be a connector between the adjacent communities, but at present is viewed by them as an undervalued resource. Proposals for development in the park area 


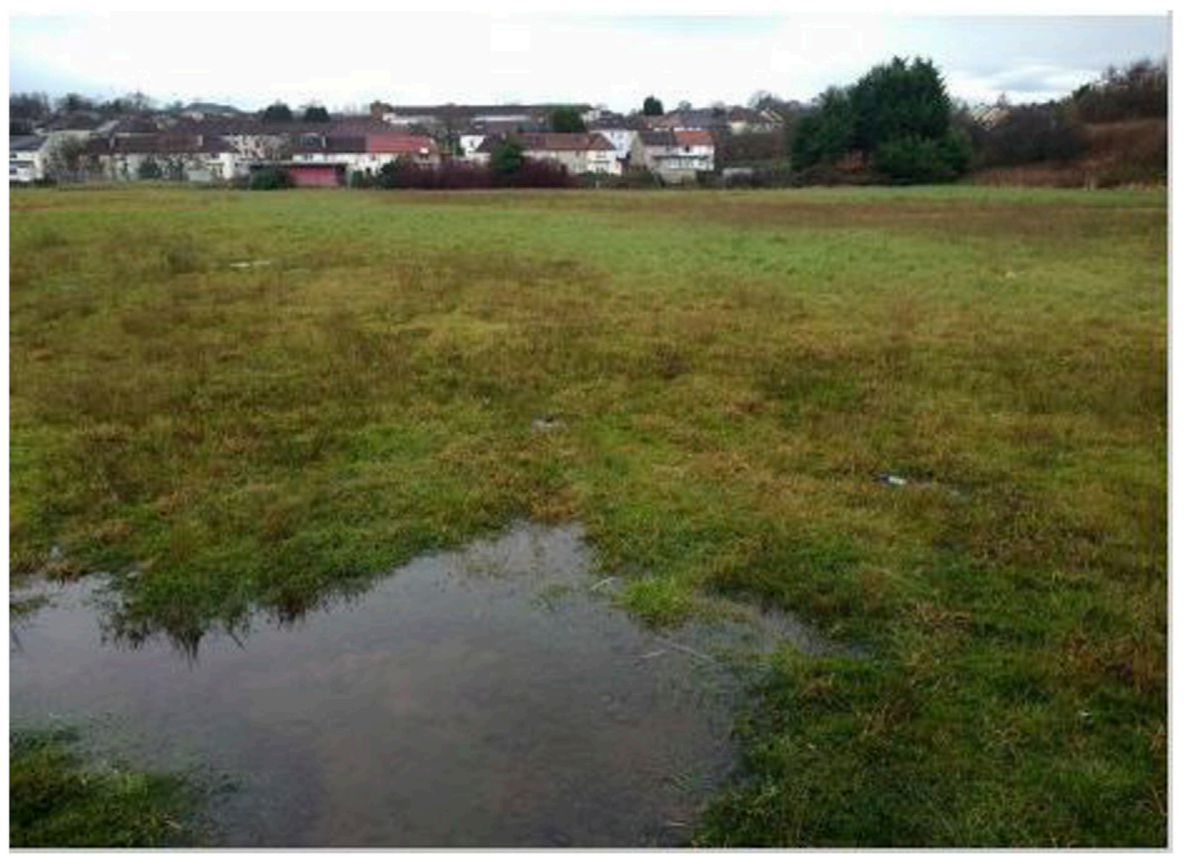

FIGURE 1 | Current land use and water problems of Glasgow park.

TABLE 1 | Community stakeholder engagement.

Phase 1 interviews

Local council departments and officials

Elected community representatives Wetland experts

Local community representatives
Neighborhoods, Regeneration and Sustainability (NRS) Development and Regeneration Services (DRS) Parks and Gardens Sustainable Glasgow team

Connecting Nature team

Waste and environmental services

Education

Planning department

SME partner

Agritech partner

Community Development Trust

Local primary schools
Phase 2 online discussion group

Parks and Gardens

Sustainable Glasgow team

Connecting Nature team

Education liaison

Community councillors

SME partner

Agritech partner

Private sector growing organisations

Community Development Trust

Local primary schools

Church food growing group

Friends of (neighbouring) park

Local community bowling club have previously been suggested but to date there has been limited capacity and vibrancy in the community to lead initiatives. Nevertheless, there are existing a number of initiatives that had the potential to be aligned with a net zero future. In particular, a local church group is engaged in small-scale food production for local consumption, the local primary is actively involved with nature based learning, and there a community centre run with the support of a Community Development Trust adjacent to the park. Together these local activities formed the basis for community engagement for the proposed wetland development. Participants from these groups as well as local representatives on the community council, elected members of the city council, and other stakeholders involved in the development of other parks in the local area participated in the community discussions and framing of the wetland development (Table 1).

In exploring the carbon reduction potential of a wetland development of the park, a two-phase approach was adopted. Firstly, a place-based framework was adopted to create a potential strategy for developing the park site. This was conducted through 


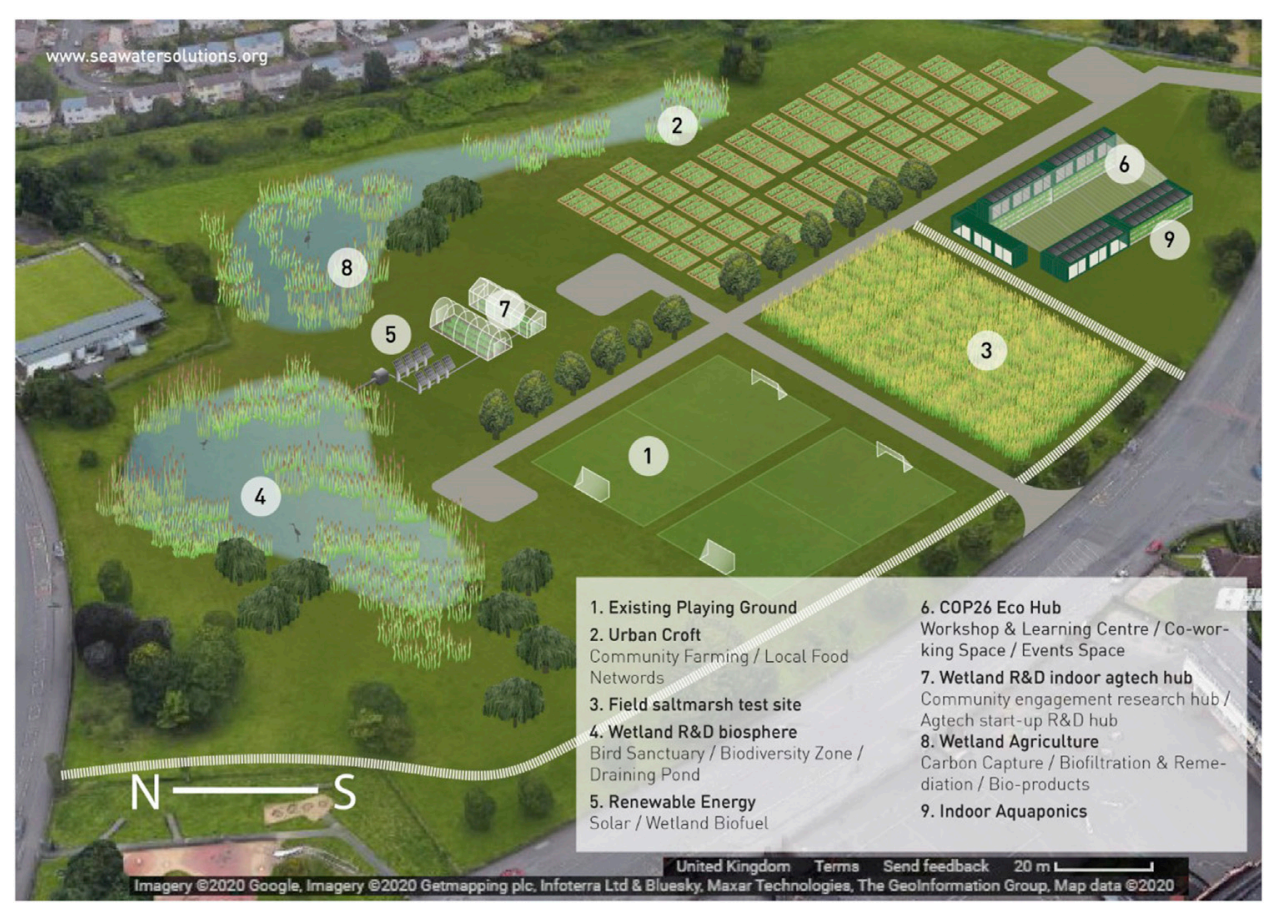

FIGURE 2 | Schematic plan for possible integrated wetland development of Glasgow park proposed by Seawater Solutions.

a series of 14 semi-structured one to one interviews with key stakeholders, including the Small and Medium Sized Enterprise (SME) as wetland experts, key policy decision makers within the local authority, community group representatives and parkland users. Second, using the outcome of the above, two online workshops were held with community stakeholders (Table 1) seeking views and comments on the proposal, identifying potential benefits for the local communities, and also perceived barriers to enabling the development to take place. Additional research and stakeholder engagement focussed on feasible business models were held, but this is considered beyond the scope of this paper. Contemporaneous desk-based review of the carbon capture efficacy of urban wetlands and potential for income generation through carbon credit was undertaken by the research team.

\section{DATA}

The outcome of the first stage of the process, an analysis of the interview records, was an outline schematic proposal for the site (Figure 2) that enabled exploration of benefits it might offer to the city council in meeting their carbon net zero targets, both directly through the construction and management of an artificial urban wetland, and less directly as part of an integrated community development project. This formed the input to the second stage of wider community engagement, using the schematic proposal to initiate, and focus discussion.

In addition, the proposal formed the basis for an assessment of potential carbon reduction. The plan sought to blend different interventions designed to provide benefits in carbon reduction assisting in an understanding of the role that urban wetlands could play in contributing to net zero carbon ambitions. It drew on the recent Taskforce for Scaling Voluntary Carbon Markets (2020) report which identified that deprived neighbourhoods could benefit from carbon credits generating flows of private capital into these communities. To this end, it specifically examined the potential for carbon drawdown by urban wetland systems, the factors that influence this, and the potential for generation of revenue from urban wetland carbon capture through market-based monetisation of carbon crediting. Possible business cases were developed to allow a carbon credit scheme to be adopted, using pricing, regulatory and monitoring parameters under the Peatland Core UK [PeatlandCode_vl.1_ FINAL.pdf (iucn-uk-peatlandprogramme.org)].

\section{RESULTS}

The case study provided an opportunity to explore two key elements of how artificial urban wetlands could possibly contribute to net zero pathways; firstly, through a direct contribution to carbon reduction and sequestration supported by carbon credit schemes; and secondly, through more indirect carbon reduction as part of an integrated community development project.

\section{Constructed Wetlands and Carbon Net Zero}

To date, there has been notably little focus on quantifying the carbon capture potential of urban artificial wetlands, and how 
these could fit with net zero ambitions for communities. Existing scientific research indicates that healthy wetlands are net carbon sinks (de Klein and Van der Werf, 2014). However, unhealthy or disturbed wetlands are net carbon sources (Were et al., 2019) emitting carbon dioxide $\left(\mathrm{CO}_{2}\right)$, methane $\left(\mathrm{CH}_{4}\right)$ and nitrous oxide $\left(\mathrm{N}_{2} \mathrm{O}\right)$ (Mitsch et al., 2013). A number of factors affect the balance of carbon sequestered and greenhouse gases emitted, including soil type, species type, hydrology and drainage, climate and abundance and species of microbial species (Mitsch et al., 2013; de Klein and Van der Werf, 2014; Were et al., 2019). Consequently, there is agreement that understanding - and engineering-a net negative carbon balance is important for ensuring the climate action objectives are met by constructed wetland initiatives (Were et al., 2019).

Achieving this as part of constructed wetlands however remains elusive. Relatively little is understood of the carbon balance complexities of wetlands, and there is identified need for more research in this topic (de Klein and Van der Werf, 2014; Were et al., 2019). In particular, there is very little understanding of the length of time required to establish a net negative carbon wetland system for constructed wetland. It is clear nevertheless that the way in which artificial wetlands are designed and maintained could be engineered to support the carbon sequestration potential (Were et al., 2019). For most types of wetlands, the bulk of sequestered carbon is in the soils rather than in the plant communities and thus it is when the soil rather than the surface growth is disturbed (physically, or through change in environmental conditions) that carbon release is greatest (Dusek et al., 2020). Approaches to enhance wetland carbon capture efficacy include ensuring that optimal conditions (appropriate to the specific environment or species) are maintained, or through environmental engineering approaches such as selecting soil microbial and plant communities, fine-tuning $\mathrm{pH}$, or adding key nutrients or biochar (Were et al., 2019).

The key conclusion from this exploratory research suggested that artificial urban wetlands of the scale and form envisaged in the Glasgow case study would be unable to be justified through its direct contribution to net zero targets. That said, it also revealed significant knowledge gaps and that make any such analysis challenging.

Firstly, there are many uncertainties within the wetland carbon systems, with the current understanding of the occurrence and variability of carbon storage between wetland types and across regions (Carnell et al., 2018) representing a major impediment to the ability of nations to include wetlands in greenhouse gas inventories and carbon offset initiatives. To date, in current peer reviewed literature, there has been no attempt to quantify the carbon captured through urban farming initiatives associated with or enabled by the artificial wetland. As well as making the carbon capture impacts of urban wetland creation challenging to directly ascertain, this gap also brings financial implications. It is difficult to quantify whether the carbondrawdown through wetland project will be sufficient to be recognised in carbon credit schemes currently available in the $\mathrm{UK}$, devaluing one obvious pathway to using wetlands as part of city-wide carbon reduction programmes.
The second challenge regards scaling issues; artificial urban wetlands will have a small footprint and correspondingly small carbon capture potential compared to natural wetland landscapes. Moomaw et al. (2018) estimate that the area of new wetlands needed to remove $1 \%$ of the current annual increase in atmospheric $\mathrm{CO}_{2}$ is about $2,000,000 \mathrm{~km}^{2}$. As a result, emphasis on wetland carbon capture systems tends to conclude or imply that (i) priority should be on the retention of existing wetlands as their contribution is significant and difficult to replace and (ii) that new or restored wetlands have to be of significant scale globally to make a marked impact on climate change. However, this overlooks how multiple distributed small scale urban wetland systems could contribute to carbon sequestration efforts; a potential that might be realised in schemes such as Melbourne's 600 constructed wetlands project.

It's important to note also that, in the case study context-i.e., underused urban land-a priority for site selection was not carbon capture capacity or efficacy. Land constraints in cities and communities will likely mean that prospective sites for blue-green infrastructure will not be optimised for carbon drawdown. In that sense, carbon capture will not be a primary driver. Rather, carbon capture efficacy will be secondary or even tertiary to factors such as land value, land ownership, propensity to flooding, and other social or sustainability factors in line with local and regional priorities. This is not only important for understanding the role of SMEs in supporting carbon drawdown initiatives in the urban environment, but also important in understanding financial enablers or, put differently, the business case for blue-green infrastructure for climate action. This begs the question whether the current focus on artificial wetland creation for climate adaptation and resilience-such as storm-water management-is simply easier to constrain, and therefore justify, in an integrated approach. For the case study project, given that, under current models, the selected site does not have clear value for carbon sequestration, other benefits that might be offered became increasingly important. This indicates a need for more empirical research to test the viability of business models in the community setting within different urban environments.

\section{Collaboration Towards Shared Value Beyond Carbon}

In the absence of clear evidence of how urban wetlands can contribute directly to carbon reduction strategies, a new approach is required which seeks to connect urban wetlands into communities, reconceiving, and repositioning artificial urban wetlands as one component of a socio-environmental ecosystem of development to contribute to carbon net zero ambitions and other associated sustainability objectives. The Glasgow case study provides one example of how such a pathway can be constructed.

Here an integrated approach was essential, as there was a requirement to balance the objectives of the SME (developing wetland systems) with those of the local authority (carbon net zero), and indeed the local community (improved community asset). For the SME, an expedited planning process was desirable 
in order to take an agile approach to testing and developing models for carbon sequestration on site. Land in local authority land ownership is therefore preferential, in particular land in areas with established surface water drainage challenges. Development on such sites necessitates a comprehensive engagement with both GCC and adjacent communities, and the consideration of longer-term strategic objectives and capacities. For the local authority, a primary concern was that any development would not add to the maintenance budget, or limit the capacity within the parks department to fund the management of costly infrastructure going forward. Aligned to this was the need to maximise community benefits from any development on public land, with an obvious social value to the local community. For all stakeholders, the need to build a business case that could marry social, environmental, and economic objectives became obvious in order to progress development of the urban wetlands. At this scale, as noted above, wetlands development is currently not possible using carbon credits as a business mechanism, decentisiving private investment. However, prototyping models for wetlands by providing public land to a profit-making enterprise without a clear social return on investment (beyond the environmental value) understandably puts councils in a difficult position.

Emerging from interviews with local authority departments, a number of policy objectives were identified that could allow for socially innovative business models through the combination of uses on site. In particular, these included opportunities to align additional activities on site to policy ambitions in areas such as food-security, health and education. Chief among these is the council's Glasgow City Food Plan, which seeks to increase understanding of the food system especially with regards to nutrition and sustainability, and calls for more opportunities for communities to enjoy cooking and growing together. Similarly, the city's Open Space Strategy, prioritises the long term resilience of the city in relation to issues such as climate change, liveability, and the health of its population, flora and fauna-as a partner on the Horizon 2020 funded Connecting Nature programme. Further stakeholder engagement with local schools identified specific opportunities related to Scotland's Curriculum for Excellence through outdoor learning. One school immediately opposite the site has no outdoor space whatsoever, while another buses children to another park some miles away. Dynamic policy development in the context of the COVID-19 pandemic has reiterated calls for better quality open space to allow for compliant social distancing, and to mitigate the consequences of quarantine.

In this case, the co-development of vacant or underused urban infrastructure such as parks and wetlands presented a focus for arriving at shared outcomes among a number of stakeholder groups seeking wider social transformation in areas related to health and well-being, and social exclusion. Local community development groups saw the opportunity for spaces that accommodate services in areas such as skills and employment, sports and circular economy, alongside socially innovative provisions to support efforts related to obesity, alcohol, and drug addiction. Through sensitive engagement with those key stakeholders, other community needs, and benefits were identified that could be manifest on site, developed iteratively following a participatory process. In developing an early masterplan with the SME, community stakeholders proposed several early concepts for social services included allotments, outdoor classrooms and sports facilities-linking to outcomes for education, health and well-being and wider policy agendas. While concepts for the park site remain open, inviting the community into the brief-making process as early as possible will ideally raise the prospect of community support for the development in the planning process, and local ownership over any spatial intervention. For the local authority this would support a more manageable legacy outcome, the potential of literal community ownership-through community asset transfer-where the infrastructure would be ultimately devolved to the community.

Using this place-based approach to developing a shared vision of the park's future, a more robust and sustainable business case based on carbon reduction strategies was possible. Through innovative use of agri-technologies and wetland carbon capture to sit alongside onsite renewable energy production, reinforced by enhancing the community asset development of the site for local use and education purposes, the project demonstrated that it had the potential to contribute to the city's net zero targets. This more complex, multifunctional and multi-stakeholder was thus a more credible and achievable way in which artificial wetlands could, albeit more indirectly, be a pathway to net zero.

\section{DISCUSSION}

\section{Realising Integrated Blue-Green Infrastructure in Practice}

The case study presented here explored the multiple benefits that could be achieved through the development of an integrated constructed urban wetland. It provides a basis to establish whether and how urban wetlands could contribute to a city's net zero targets, and for testing an integrated urban planning approach to support multiple sustainability objectives.

Integration to support multiple co-benefits beyond water management has implications for how new urban wetlands are designed and implemented, and how they are supported in the planning process. For example, O'Donnell et al. (2017) found that in order to overcome barriers that have constrained the adoption of blue-green infrastructure, there is merit in looking beyond water management benefits, which is traditionally the central rationale for investment in wetland construction. They suggest that promoting these areas as multifunctional space can be vital to ensure local support, looking beyond what is statutory required to implement projects. Co-benefits associated with projects to reduce carbon include increased biodiversity, job creation, and health benefits from improved air quality. Communicating multiple benefits, which are contextual and extend into the socio-cultural, ecological, and economic spheres, could greatly increase public confidence and open up avenues for co-funding schemes to support development of blue-green infrastructure (Ashley et al., 2015). Active engagement supports the behavioural 
and cultural change required for communities to embrace artificial wetlands contrasting to traditionally speculative approaches to development in cities (O'Donnell et al., 2017). Additional synergies between green technologies and urban quality of life can also arise in areas where wetlands are a key part of an integrated water management approach. Studies in China, USA, and Australia have suggested that both the distance to the nearest wetland and the number of wetlands within close proximity significantly influence a number of other propertyspecific and neighbourhood attributes, including social mix (Boyer and Polasky, 2004; Tapsuwan et al., 2009; Du and Huang, 2018). Since the COVID-19 pandemic in particular, there is growing recognition of the role wetlands play in providing ecosystem services, improving outcomes for physical and psychological health, increased community stewardship and sense of place.

However, an integrated approach goes beyond public support and uptake. Without integration, the multi-functionality will be limited. Gómez Martín. (2021) apply a system thinking approach to assess the contribution of nature based solutions to multiple SDGs, and conclude that engaging stakeholders in the very first stages of design and implementation is key to maximising sustainability benefits. Embedded social innovation, that requires the co-construction of solutions, addresses the democratic deficit in planning at the community level giving the community oversight-and ownership-over the development process (Horgan and Dimitrijević, 2021). This follows Arnstein's (1969) scale of eight levels of community participation, and his call for improved feedback loops to facilitate knowledge transfer between the community and design team, prioritising engagement as early as possible in the design process (Arnstein, 1969). The greater partnership approach taken in the Glasgow case sits high on Arnstein's (1969) scale, moving toward delegated power and full citizen control, where targeted collaboration among stakeholders and end users can deliver impact that offsets spatial imbalances and short-termist politics in planning. Realising integrated systems in practice remains challenging, meaning that community engagement-to shape a brief and vision for development-should begin at the earliest opportunity.

An integrated, community embedded, approach to urban bluegreen infrastructure requires changing how it is planned and delivered, seeking greater collaborative working and participation from a range of agencies with diverse remits and objectives. The Glasgow study provides a glimpse at how, through facilitated discussion with local organisations, a framework for wetlands construction could be realised in practice-transforming the currently underused land into a thriving restored ecosystem contributing to the local economy, population, and wildlife through improved environmental standards, green access, economic, and career opportunities. Collective stakeholders united around the concept of a "living lab," providing an innovative blend of wetland outdoor and indoor agricultural production along with learning spaces and community-focused assets all linked to the creation of more sustainable and local food production, leading to better outcomes for citizens. Such a prototype could be replicated in similar living labs and facilities in other communities globally, and elaborated upon following a service design methodology to propose potential services with local citizens. The concept represents an opportunity to develop a model for genuine community engagement and participation, centring the community as key stakeholders in the co-design and codelivery of the living lab. Linking community development projects with wider sustainability outcomes and vice versa calls for new capacities and a nuanced approach to community education and engagement.

\section{CONCLUSION}

Artificial urban wetlands are known to bring benefits in terms of water management and habitats that contribute to the sustainability of social ecological systems. At the local level, and to ensure that they become key parts of carbon net zero pathways, investment in restorative wetlands depends on the ability to build a strong business case that considers initiatives such as carbon sequestration alongside other functions, within a holistic masterplan. Encouraged by frameworks for community resilience informed by an ecology for cities, this paper explored the potential for such blue-green infrastructure to bring other sustainable development benefits so far overlooked.

Drawing on a unique case study pilot project, this paper has considered possible pathways by which such wetlands can contribute direct to carbon reduction through sequestration and carbon trading, and indirectly as part of community development projects. It has sought to help fill a knowledge gap exploring how in practice artificial urban wetlands can make a contribution to carbon net zero futures. It concludes that the potential of wetlands to sequester carbon needs to be augmented by other carbon-reduction actions, including using wetlands for food production for local markets and in turn displacement of carbon-heavy transportation of food, or utilising local renewable energy sources to provide heat, electricity, and potential for local grid networking to community assets. However, like many other nature-based initiatives the process of embedding projects such as the Glasgow case study into mainstream net zero strategies requires further analysis. As Bulkeley et al. (2021) note, many nature-based solutions are not being implemented through long-term planning frameworks or as a result of local regulation concerning the use and management of urban nature. Instead, they are a form of governance by experimentation in which urban sustainability is pursued through a patchwork of initiatives and projects which bring together diverse actors.

Under such approaches, in terms of carbon capture efficacy of artificial urban wetland sites as a contribution to net zero targets, it remains difficult to identify more generic conclusions, and will likely be context specific according to factors such as environmental conditions, species, as well as maintenance. More research is needed to investigate the potential for carbon capture and environmental engineering approaches to enhance carbon drawn down, including long-term maintenance needs. At an urban scale, the carbon drawdown is likely to be small, and unlikely to be eligible for currently available carbon credit schemes. This indicated a need for research on mechanisms for modular credits for, say, city-wide artificial wetland infrastructure. 
In addition, the multiple constraints placed on development land in cities from the perspective of urban governance, impacts greatly on site selection, means that sites that will be most effective at capturing carbon are not always the most appropriate for urban wetlands development. For this reason, sites that help to realise other sustainability objectives where carbon is not a primary driver may realise greater co-benefit than those with optimal carbon drawdown. In this study, site selection was governed by land ownership and overall fit with strategy, which altered the values underpinning the project more generally. This process-and responsibilities of the SME to envisage wider community benefit-would have been considerably different in the context of a development on land in private ownership.

However, the Glasgow case study points to how significant contributions to net zero targets can be achieved associated with, for example, using local food production to help reduce and offset carbon emissions, or utilise local renewable energy sources to provide heat, electricity, and potential for local grid networking to community assets. Through experimental project-based activities with stakeholders, the living lab could be used to demonstrate the effectiveness of urban wetlands as carbon sinks, natural flood barriers, and remediation tools in an urban setting. Programming use of the site for educational purposes to raise awareness of urban agri-technology solutions through education and outreach programmes, inspiring a new generation of urban farmers, agriculturalists and consumers can deliver significant indirect benefits towards net zero targets and stimulate longterm job creation in maintenance and operations for local people. Initiatives that support apprenticeship and similar schemes to upskill local people in food production and greenspace management may increase potential for community asset transfer and the local management of public assets through capacity building and participation in design and decision-making.

The historic focus on urban wetlands as water management tools, and as discrete landscapes separated from the surrounding built-up urban environment, has inhibited the full benefit that integrated approach can unlock. A new approach is required which seeks to connect urban wetlands into communities, reconceiving, and repositioning artificial urban wetlands as one component of a socio-environmental ecosystem of development to contribute to carbon net zero ambitions and other associated sustainability objectives. The demonstrator project suggests that crucially constructed wetlands need to be integrated into wider re-development initiatives in cities, where the potential of wetlands to sequester carbon is augmented by other carbon-reduction actions. These include using wetlands for food production for local markets and in turn displacement of

\section{REFERENCES}

Ahn, C., and Schmidt, S. (2019). Designing Wetlands as an Essential Infrastructural Element for Urban Development in the Era of Climate Change. Sustainability 11 (7), 1920. doi:10.3390/su11071920

Arnstein, S. R. (1969). A Ladder of Citizen Participation. J. Am. Inst. Planners 35 (4), 216-224. doi:10.1080/01944366908977225 carbon-heavy transportation of food, and for renewable energy. The scope and realisation of such projects must be place-based and stakeholder and community led. In so doing, there is strong potential for them to contribute more to climate change mitigation and adaptation strategies in cities-and indeed to sustainable development more broadly.

\section{DATA AVAILABILITY STATEMENT}

Publicly available datasets were analyzed in this study. This data can be found here: www.ifuturecities.com.

\section{AUTHOR CONTRIBUTIONS}

This paper draws on research conducted with communities and stakeholders in Glasgow. The community engagement was led by RR who was responsible for the review of previous research on artificial urban wetlands. The wider discussion on place based approaches and on the policy context was conducted by DH. JR was lead researcher on the contribution of wetlands to carbon sequestration and net zero targets.

\section{FUNDING}

This project was funded by Innovate UK through the UK Government Sustainable Innovation Fund Small Business Research Initiative which ran from October to December 2020. Grant reference No. 76575. The researchers at the University of Strathclyde were sub-contracted by Seawater Solutions, a Glasgow based ecoservices company, to conduct research as part of a wider project on possible urban wetland demonstrators for carbon capture. The views expressed in this publication are those of the authors and not necessarily those of Innovate UK.

\section{ACKNOWLEDGMENTS}

We thank the project team, and in particular the SME who instigated the project, Glasgow City Council, and Alejandro Mar Morales for detailed review of potential carbon credit pathways for wetland systems. We also gratefully acknowledge the input from all stakeholders who participated in interviews and workshops to shape the study, and to the two referees for their insightful suggestions to improve an earlier draft of the paper.

Ashley, R., Walker, L., D’Arcy, B., Wilson, S., Illman, S., Shaffer, P., et al. (2015). UK Sustainable Drainage Systems: Past, Present and Future. Proc. Inst. Civil Eng. Civil Eng. 168 (3), 125-130. doi:10.1680/cien.15.00011

Boyer, T., and Polasky, S. (20040744). Valuing Urban Wetlands: a Review of Non-market Valuation studiesVUWARO]2.0. WetlandsCO 24 (4), 7442-7755. doi:10.1672/02775212(2004)02410.1672/0277-5212(2004)024[0744:vuwaro]2.0.co;2

Bulkeley, H., Kok, M., and Xie, L. (2021), Realising the Urban Opportunity: Cities and post-2020 Biodiversity Governance. The Hague: PBL Netherlands 
Environmental Assessment Agency Realising the Urban Opportunity: Cities and post-2020 Biodiversity Governance (pbl.Nl).

Carnell, P. E., Windecker, S. M., Brenker, M., Baldock, J., Masque, P., Brunt, K., et al. (2018). Carbon Stocks, Sequestration, and Emissions of Wetlands in South Eastern Australia. Glob. Change Biol. 24 (9), 4173-4184. doi:10.1111/gcb.14319

Childers, D., Cadenasso, M., Grove, J., Marshall, V., McGrath, B., and Pickett, S. (2015). An Ecology for Cities: A Transformational Nexus of Design and Ecology to advance Climate Change Resilience and Urban Sustainability. Sustainability 7 (4), 3774-3791. doi:10.3390/su7043774

Childers, D. L., Pickett, S. T. A., Grove, J. M., Ogden, L., and Whitmer, A. (2014). Advancing Urban Sustainability Theory and Action: Challenges and Opportunities. Landscape Urban Plann. 125, 320-328. doi:10.1016/ j.landurbplan.2014.01.022

Das Gupta, A., Sarkar, S., Ghosh, P., Saha, T., and Sil, A. K. (2016). Phosphorous Dynamics of the Aquatic System Constitutes an Important axis for Waste Water Purification in Natural Treatment Pond(s) in East Kolkata Wetlands. Ecol. Eng. 90, 63-67. doi:10.1016/j.ecoleng.2016.01.056

Davenport, M. A., Bridges, C. A., Mangun, J. C., Carver, A. D., Williard, K. W. J., and Jones, E. O. (2010). Building Local Community Commitment to Wetlands Restoration: A Case Study of the Cache River Wetlands in Southern Illinois, USA. Environ. Manag. 45 (4), 711-722. doi:10.1007/s00267-010-9446-x

Davidson, N. C. (2014). How Much Wetland Has the World Lost? Long-Term and Recent Trends in Global Wetland Area. Mar. Freshw. Res. 65 (10), 934-941. doi:10.1071/MF14173

de Klein, J. J. M., and van der Werf, A. K. (2014). Balancing Carbon Sequestration and GHG Emissions in a Constructed Wetland. Ecol. Eng. 66, 36-42. doi:10.1016/j.ecoleng.2013.04.060

$\mathrm{Du}, \mathrm{X}$., and Huang, Z. (2018). Spatial and Temporal Effects of Urban Wetlands on Housing Prices: Evidence from Hangzhou, China. Land use policy 73, 290-298. doi:10.1016/j.landusepol.2018.02.011

Dusek, J., Darenova, E., Pavelka, M., and Marek, M. (2020). "Methane and Carbon Dioxide Release From Wetland Ecosystems," in Climate Change and Soil Interactions. Editors M. Prasad and M. Pietrzykowski (Oxford: Elsevier), 509-553. doi:10.1016/B978-0-12-818032-7.00019-9

Finger, M. (2018). Smart City-Hype And/or Reality? IGLUS Q. 4 (1). accessed at Smartcity - Hype or Reality? - SocietyByte.

Furlong, C., Gan, K., and De Silva, S. (2016). Governance of Integrated Urban Water Management in Melbourne, Australia. Utilities Policy 43, 48-58. doi:10.1016/j.jup.2016.04.008

Glasgow City Council (2020). Climate Emergency Implementation Plan. available at: https://www.glasgow.gov.uk/CHttpHandler.ashx?id=50623\&p=0.

Glasgow City Council (2014). Energy and Carbon Masterplan. available at: https:// www.glasgow.gov.uk/CHttpHandler.ashx?id=32441\&p=0.

Gómez-Martín, M. E., Gimenez-Carbo, E., Andrés-Doménech, I., and Pellicer, E. (2021). Boosting the Sustainable Development Goals in a Civil Engineering Bachelor Degree Program. Int. J. Sustain. High. Educ. 22 8, 125-145. doi:10.1108/IJSHE-02-2021-0065

Greenfield, A. (2017). Radical Technologies: The Design of Everyday Life. London: Verso Books. 978-1-78478-043-2.

Horgan, D., and Dimitrijević, B. (2019). Frameworks for Citizens Participation in Planning: From Conversational to Smart Tools. Sust. Cities Soc. 48, 101550. doi:10.1016/j.scs.2019.101550

Horgan, D., and Dimitrijević, B. (2021). Social Innovation in the Built Environment: the Challenges Presented by the Politics of Space. Urban Sci. 5 (1), 1. doi:10.3390/urbansci5010001

Horgan, D., and Dimitrijević, B. (2018). Social Innovation Systems for Building Resilient Communities. Urban Sci. 2 (1), 13. doi:10.3390/urbansci2010013

Horgan, D. (2020). Placemaking. In: A. Kobayashi (Ed.), International Encyclopedia of Human Geography, 2nd edition. Vol. 10, Elsevier, pp.145-152. doi:10.1016/B978-0-08-102295-5.10680-8

Hu, S., Niu, Z., Chen, Y., Li, L., and Zhang, H. (2017). Global Wetlands: Potential Distribution, Wetland Loss, and Status. Sci. Total Environ. 586, 319-327. doi:10.1016/j.scitotenv.2017.02.001

Jacobs, J. (1961). The Death and Life of Great American Cities. New York: Vintage Digital.
Maes, M. J. A., Jones, K. E., Toledano, M. B., and Milligan, B. (2019). Mapping Synergies and Trade-Offs between Urban Ecosystems and the Sustainable Development Goals. Environ. Sci. Pol. 93, 181-188. doi:10.1016/j.envsci.2018.12.010

Mitchell, R., Beck, S., Cadell, J., Combe, J., Dawson, E., Lawlor, D., et al. (2014). A Place Standard for Scotland. Eur. J. Public Health 24 (Suppl. 1_2), 15. doi:10.1093/eurpub/cku162.064

Mitsch, W. J., Bernal, B., Nahlik, A. M., Mander, Ü., Zhang, L., Anderson, C. J., et al. (2013). Wetlands, Carbon, and Climate Change. Landscape Ecol. 28, 583-597. doi:10.1007/s10980-012-9758-8

Moomaw, W. R., Chmura, G. L., Davies, G. T., Finlayson, C. M., Middleton, B. A., Natali, S. M., et al. (2018). Wetlands in a Changing Climate: Science, Policy and Management. Wetlands 38, 183-205. doi:10.1007/s13157-0181023-8

O’Donnell, E. C., Lamond, J. E., and Thorne, C. R. (2017). Recognising Barriers to Implementation of Blue-Green Infrastructure: a Newcastle Case Study. Urban Water J. 14 (9), 964-971. doi:10.1080/1573062X.2017.1279190

Oral, H. V., Carvalho, P., Gajewska, M., Ursino, N., Masi, F., Hullebusch, E. D. v., et al. (2020). A Review of Nature-Based Solutions for Urban Water Management in European Circular Cities: a Critical Assessment Based on Case Studies and Literature. Blue-Green Syst. 2, 112-136. doi:10.2166/ bgs.2020.932

Ostrom, E. (2007). A Diagnostic Approach for Going beyond Panaceas. Proc. Natl. Acad. Sci. 104 (39), 15181-15187. doi:10.1073/pnas.0702288104

Ozawa-Meida, L., and Alajmi, A. (2021). Aligning Local Interventions with the UN Sustainable Developments Goals (SDGs). Leicester: University of Leicester.

Pickett, S. T. A., McGrath, B., Cadenasso, M. L., and Felson, A. J. (2014). Ecological Resilience and Resilient Cities. Building Res. Inf. 42 (2), 143-157. doi:10.1080/ 09613218.2014.850600

Scottish Council for Voluntary Organisations (2018). The Global Goals for Sustainable Development: Scotland's Goals. SCVO, XXXX. Available at: https://globalgoals.scot/scotlands-goals/.

Scottish Government (2020). Fourth National Planning Framework: Position Statement. Edinburgh: Scottish Government. 9781800041943.

Scottish Government (2018). The 'place Principle': A Shared Context for Place-Based Work. Edinburgh: Scottish Government. Available at: https://www. improvementservice.org.uk/_data/assets/pdf_file/0026/9548/place-principle.pdf.

Tapsuwan, S., Ingram, G., Burton, M., and Brennan, D. (2009). Capitalized Amenity Value of Urban Wetlands: a Hedonic Property price Approach to Urban Wetlands in Perth, Western Australia. Aust. J. Agric. Resource Econ. 53 (4), 527-545. doi:10.1111/j.1467-8489.2009.00464.x

Taskforce for Scaling Voluntary Carbon Markets (2020). Consultation Paper, November (TSVCM_Consultation_Document.Pdf (iif.Com))

Were, D., Kansiime, F., Fetahi, T., Cooper, A., and Jjuuko, C. (2019). Carbon Sequestration by Wetlands: A Critical Review of Enhancement Measures for Climate Change Mitigation. Earth Syst. Environ. 3, 327-340. doi:10.1007/ s41748-019-00094-0

Conflict of Interest: The authors declare that the research was conducted in the absence of any commercial or financial relationships that could be construed as a potential conflict of interest.

Publisher's Note: All claims expressed in this article are solely those of the authors and do not necessarily represent those of their affiliated organizations, or those of the publisher, the editors and the reviewers. Any product that may be evaluated in this article, or claim that may be made by its manufacturer, is not guaranteed or endorsed by the publisher.

Copyright $\odot 2021$ Rogerson, Horgan and Roberts. This is an open-access article distributed under the terms of the Creative Commons Attribution License (CC BY). The use, distribution or reproduction in other forums is permitted, provided the original author(s) and the copyright owner(s) are credited and that the original publication in this journal is cited, in accordance with accepted academic practice. No use, distribution or reproduction is permitted which does not comply with these terms. 